\title{
PROFESSIONAL DEVELOPMENT IN GERONTOLOGY*
}

\author{
Wilma DONAHUE, Ph.D. $\dagger$ \\ Institute for Human Adjustment, Division of Gerontology, University of Michigan, \\ Ann Arbor, Michigan
}

"This is only the third year (1959) that the American Orthopsychiatric Association has included aging among the topics for scientific consideration and for publication in its journal." (Maurice Linden.)

This statement reflects accurately the state of affairs in most areas of scientific investigation and interest with reference to aging. The emergence of individual and social needs has far outdistanced the development of a scientific body of knowledge about aging persons and about the effect of demographic and cultural factors on society. A further reflection of the failure of science and education to keep pace with changes brought about by the increasing numbers of older people and their altered status in the population has been the lack of opportunities for professional training in gerontology. Without the systematic organization and conceptualization of the subject matter of gerontology and without the training of scientists in the emerging field, the lag in scientific and professional concern cannot readily be accelerated. This paper is concerned with a statement of a) early efforts and current developments, b) the emergence of social gerontology, and c) a training project in social gerontology.

\section{EARLY EFFOR'TS AND CURRENT DEVELOPMENTS}

Modern gerontology has its roots in the efforts of two committees, both of which were active in the middle 1940's. One of these, essentially biologically and medically oriented, was supported by the Macy Foundation and was known as the "Research Club for Aging." The other committee was established by the Social Science Research Council, and was concerned with the social adjustments required to accommodate an aging population. The members of these two committees became the core from which the Gerontological Society, Inc. was formed in 1947 , thus giving formal recognition to a new scientific area of major interest. The development of the field by research and teaching personnel in colleges and universities did not, however, immediately take place. It is only within the last three or four years that real progress began.

\section{Medical schools}

Since medical science has been the heaviest contributor to the improvement in mortality rates, it is natural to assume that it would be the first to be concerned with training its members to cope with the effects of increased longevity upon the physical and mental health of masses of people.

* Presented at the 36th Annual Meeting of the American Orthopsychiatric Association, San Francisco, California, March 30-April 1, 1959.

$\dagger$ Chairman, Planning Committee, Institute for Human Adjustment, Division of Gerontology, University of Michigan, 1510 Rackham Building, Ann Arbor, Michigan. 
This, however, has not been the case - in part perhaps because an issue immediately arose as to whether geriatrics is a medical speciality and whether geriatricians should have a place in the spectrum of specialities.

For example, a seminar on the question of professional training in geriatrics which was held in connection with the University of Michigan Ninth Annual Conference on Aging (1) was made up of 170 representatives of medical schools, the Veterans Administration, and the Public Health Service. A spirited discussion quickly brought general agreement that departments of geriatric medicine would be unwelcome additions to medical schools.

At the same time, the group recognized that there was a problem and offered the following recommendations for its solution:

"In view of the relatively small numbers of teachers qualified in the field of gerontology, it seems wise to establish graduate departments in selected medical schools. The function of these departments would not be to turn out large numbers of graduates who could practice geriatrics as a speciality, but to produce investigators and teachers in this field."

The modus operandi recommended to achieve these goals would be a coordinator for aging who might be a member of any medical school department, although it was assumed that he would be in the department of internal medicine. He would head an interdepartmental committee concerned with incorporating appropriate material on aging into the curriculum content of each department, would spark research, and would serve as a liaison officer with the generaI university. Dacso (2) has elaborated this scheme in considerable detail and urges the inclusion of aging in all aspects of the medical training program.

In spite of generally negative attitudes, a few medical schools are forging ahead with research and instructional programs in gerontology. The University of Kansas was the first medical school to recognize the new field by establishing a chair in geriatrics about 1954. Duke University Medical School in 1957 became the site of the first Regional Center for Aging Research, with the support of a $\$ 1,500,000$ grant from the Public Health Service, which amount has been recently augmented by another grant of $\$ 388,000$ from the same source for a building to house the Research Center. In all fairness, it should be pointed out that this Center did not spring full blown, like Minerva from the head of Jupiter. Its director, Dr. Ewald Busse, had organized a team of workers at the University of Denver early in the 50's, and this team later moved to Duke University to continue its gerontological studies there. Albert Einstein College of Medicine in 1958 also received from the Public Health Service a grant of $\$ 417,939$ to establish a geriatrics unit for the training of medical personnel and to conduct geriatric research. The other, and most recent medical school, to join this group is the University of Miami, Florida, which has just announced that it has added a department of gerontology under the direction of Dr. Samuel Gertman. This department will have responsibility not only for training medical personnel but for giving leadership in the training of social scientists and professional workers. May we not predict that a trend is in the making, especially when we consider 
that the annual appropriation by Congress for the National Institutes of Health is in excess of $\$ 200,000,000$, most of which is spent on research and training, and in studies of chronic disease and of aging. A report has recently been issued on the research and training grants made by the National Institutes of Health. Of the grants that were active in January $31,1958,128$ were primarily related to gerontology. Of these, three quarters were made to members of medical school faculties. These studies and projects may well become the forerunners of more formal recognition of geriatrics as a special area for research and training in the medical schools of the country.

\section{Social sciences}

In the area of the social sciences-sociology, psychology, economics, political science and anthropology-there was considerable activity in a few university centers beginning in the late 40's. In 1948, the University of Michigan held its first annual conference on aging and the report of that meeting which appeared in the following year was the first of the Michigan publications on aging. In 1949 , the University of Chicago published the first of a long list of research studies on aging carried on at the institution. Cornell, Columbia, and the Universities of Florida and California became active in the early part of the current decade. Three state universities - Michigan in 1950, Florida in 1951, and Iowa in 1953-established institutes of gerontology whose functions were largely in research and coordination. The University of California has expanded the programs of its Institute of Child Welfare to include studies of older adults and thus to become the Institute of Human Development.

It is not surprising, then, to find that as recently as 1956 the seminar on professional training at the University of Michigan Ninth Annual Conference on Aging was ready to agree with its chairman a) that middle age and old age are identifiable periods of life having characteristics that should be studied in all of the life and social sciences, and b) that gerontology is a science in its own right and, therefore, all professional persons planning to work with older persons should have specialized training throughout their preparation in didactic instruction and field work. This seminar went a step further and identified the need for a "generalist" in gerontology who was defined as an individual who has broad knowledge of the characteristics, needs and circumstances of aging and aged persons, an understanding of aging as a social-cultural phenomenon, and a knowledge of community organizations and resources.

Three conclusions reached by the seminar were reflections of an accelerating increase of activity in the study of the behavioral and societal aspects of aging. A survey of university instruction and research made by the Division of Gerontology at the University of Michigan in 1957 showed that at that time 50 colleges and universities were offering a total of 72 courses in some phase of gerontology, and 13 others had courses in prospect for the immediate future. The survey also showed that 29 master's theses and 19 doctoral dissertations on the subject had been completed within the preceding five years. 
Obviously, in comparison with the extensive training offered in the older well established fields, the amount of academic training in gerontological research and study is negligible. The sharp up-turn of the last five years, however, indicates that there is evolving an awareness of the dimensions of a new scientific field and that increasing numbers of scientists are enlisting themselves in its study.

\section{THE EMERGENCE OF SOCIAL GERONTOLOGY}

Although by the mid 1950's the field was still not clearly defined by the researchers on aging or by the educators in their considerations of the need for specially trained personnel, these efforts were nevertheless the antecedents of a new field-social gerontology.

Social gerontology is concerned with the demographic and cultural factors in population aging, with the psychological, situational and behavioral characteristics and adjustments of aging persons, and with the effects of aging on the economic, political and social structure of society.

In its scientific aspects, social gerontology is concerned with the development of a conceptual framework for the study of the behavioral and socio-cultural phenomena of aging. In its applied phases, it aims to develop principles for guidance of those responsible for the initiation and conduct of programs designed to serve the needs of aging people and of society.

Social gerontology draws from the traditional academic disciplines but, as Harlan (3) has pointed out, "it is today becoming as distinctive in theory and method and outlook as is the study of child behavior." Adopting something of the method and viewpoint of the behavioral sciences and focusing them upon the processes of aging and the aged, there is appearing "a decidedly different perspective regarding older persons" and a new series of conceptions about aging which hitherto have been unknown.

\section{THE INTER-UNIVERSITY TRAINING INSTITUTE IN SOCIAL GERONTOLOGY}

Perhaps the precipitating agent for social gerontology can be fairly identified as the Inter-University Training Institute in Social Gerontology established in 1957.

This Training Institute is the outcome of the work of a small research committee of the Psychology-Social Sciences Section of the Gerontological Society concerned with the paucity of college courses in the field, with the increasingly insistent demands for personnel trained in both the scientific and applied fields of social gerontology, and with the growing numbers of persons seeking to be trained.

The basic issue before the Committee was how to augment the number of college and university teachers equipped to train others in the psychological, social science and applied aspects of aging in order that the latter, in turn, might insure through their own teaching, an adequate supply of persons to fill the mushrooming requirements of the new and burgeoning field. 
In July of 1956 the Committee, with financial assistance from the National Institutes of Health, convened an exploratory group ${ }^{1}$ which during a week of deliberations prepared the following recommendations:

1. That a training institute in social gerontology be established to further the training of social scientists in the field of aging, thereby increasing the number of educators prepared to offer instruction and direct research in social gerontology.

2. That the training institute be organized on a cooperative, inter-university basis involving the widest possible geographic spread of educational institutions, thus insuring that the effort be national in scope and impact.

3. That the University of Michigan Division of Gerontology be the coordinating agency for the project.

4. That the program of the training institute include:

a. The preparation and publication of systematic technical summaries of existing scientific knowledge in the psychological, social, economic and political aspects of aging.

b. Special surveys of problems and preparation of materials related to the introduction of gerontology into the curriculum, and the support of graduate students and of research.

c. An intensive four-week training institute for selected college faculty members interested in preparing to teach gerontology in their respective universities and colleges.

Pursuant to these recommendations, the following achievements can be reported to date:

1. A grant of $\$ 205,000$ was made to the University of Michigan by the National Institutes of Health in January 1957, in support of the Leadership Training Institute of Social Gerontology.

2. Sixteen universities were invited to become cooperating institutions for the project and an Inter-University Council and Executive Committee were formed by their representatives.

3. Three handbooks have been prepared, and are currently in the process of publication by the University of Chicago Press, and will be available for distribution before the end of the year:

a. Handbook of Aging and the Individual: Psychological and Biological Aspects is the title of one of the books. It is being compiled under the editorship of Dr. James Birren. The 24 chapters of the book are organized under three general headings: 1) the theoretical and empirical foundations of gerontology, 2) the biologic bases of the behavioral aspects of aging, and 3) the characteristics of aging individuals.

b. A Handbook of Social Gerontology, the second volume, is under the editorship of Dr. Clark Tibbitts. Like the first volume, this one is also organized in three parts:

${ }_{1}$ Members of the conference were: John E. Anderson, James E. Birren, Ernest W. Burgess, Ewald Busse, Wilma Donahue, Robert W. Fleming, William Henry, Robert W. Kleemeier, Raymond G. Kuhlen, Maurice Linden, Sidney Spector, Gordon F. Streib, Samuel H. Thompson, Clark Tibbitts, Otto von Mering and Irving Webber. 
1) the background and theory of societal aging, 2) the impact of aging on individual activities and social roles, and 3 ) aging and the reorganization of society.

c. Aging in Western Cultures: A Survey of Social Gerontology is the title of the third book, which is being edited by Professor Ernest Burgess. It deals with the European and British approaches to the solution of various social problems related to aging, such as income, employment, retirement, physical and mental health, housing, family, and research needs.

These three books represent the authoritative, technical summaries and conceptual organizations of scientific and professional literature on the psychological and socio-cultural aspects of aging as it is currently understood in this country and Europe.

4. The recommendations of the planning committee for preparation of teaching aids and assessment of current research and training opportunities have also been carried out.

a. Five teaching syllabi with annotated bibliographies have been prepared and are being distributed by the Division of Gerontology, the University of Michigan. These syllabi are expected to stimulate instruction, but it is not anticipated that they will be used without modification. The titles of the syllabi indicate the fields covered: 1) Economics of an Aging Population, by Walter H. Franke and Richard C. Wilcock; 2) Psychological Aspects of Aging, by Raymond G. Kuhlen and Woodrow W. Morris; 3) The Sociology of Aging and the Aged, by Irving L. Webber and Gordon F. Streib; 4) Social Welfare and the Aged, by Gordon J. Aldridge and Fedele F. Fauri; and 5) Interdisciplinary Courses in Social Gerontology, by Bernice L. Neugarten, Robert J. Havighurst and Claire F. Ryder.

b. A survey of university instruction in social gerontology was made in 1957, and will be repeated in 1960 , in order to assess the extent and rate of introduction of training in social gerontology.

r. Another survey-Government and Foundation Support for Social Gerontologyhas already been published (4). From this survey, it is evident that there was almost a total lack of fellowships and traineeships in social gerontology when the first survey was made in 1957.

It should be pointed out that since then the National Institutes of Health have begun to support graduate student training in aging, and that programs for specialization in social gerontology were established last fall (1959) by the Department of Psychology, Washington University (St. Louis), and by the Committee on Human Development at the University of Chicago.

The survey showed that, as a result of extensive government support, the funds for research were in large supply. Since the survey was made, the Ford Foundation has included the field of aging in its grant program and has thus augmented materially the money available for research, especially with regard to university-community centered projects.

5. The other major recommendation of the planning committee has also been achieved through the holding of a four-week Summer Training Institute in Social Gerontology on the campus of the University of Connecticut, August 3-29, 1958.

Fellowships to the Summer Institute were awarded to 36 full-time teaching faculty members out of 130 applications received. The group chosen 
came from 36 different universities in 25 states and included 15 sociologists, 10 psychologists, 3 economists, 3 political scientists, 2 social workers with doctoral degrees in social science, 1 anthropologist, 1 educator, and 1 psychiatrist.

The Summer Institute program was developed around 2 basic courses. The Behavioral Aspects of Aging covered such categories as biology, psychological behavior, health and disease, and mental health. Dr. John Anderson and Dr. Ewald Busse, with the assistance of many other distinguished investigators, served as the staff for this seminar.

The other seminar--Social Aspects of Aging - was organized to cover such areas as background factors in societal aging, anthropology of aging, and institutional adaptations to aging. Dr. Clark Tibbitts and Dr. Bernice Neugarten were responsible for the instruction of this seminar, along with a panel of other experts in the field.

The two seminars were supplemented by special lectures, field trips, film programs and consultation periods. The academic fare was rigorous, but all 36 fellows completed the four-week period. They reported that they had achieved a new and comprehensive view of the field of gerontology, and several indicated that they were making commitments to gerontology as a life work.

In recognition of the success of the first Institute, the Inter-University Council sought and received from the National Institutes of Health an additional grant of $\$ 95,000$ to continue the project and to hold a second Summer Training Institute in Social Gerontology. This second Institute was held August 3-28, 1959, in Berkeley, with the University of California serving as host. Forty fellowships for the Institute were awarded. The Council again restricted the fellowships to full-time teaching faculty members; but one-fourth of the awards were made to faculty members in medicine, social work, family life, nursing and public health. The other three-fourths of the grants were made to applicants from the social sciences.

\section{CONCLUSION}

Although large strides have been taken to develop opportunities for professional development in gerontology, much remains to be done. We cannot hope to stem the tide of the problems created by the increasing numbers of older people in the population; nor can we create the kind of society in which they can achieve meaningful roles and a maximum of pleasure and well-being by establishing an occasional medical research center in gerontology and a handful of university departments offering Ph.D. degrees with specialization in gerontology. The pervasive nature of the problem, which involves all persons who succeed in living to middle age and all facets of societal life, demands nothing less than a full-scale campaign for the preparation of workers in all the professional fields concerned. 


\section{REFERENCES}

1. Professional Training in Gerontology; Summary and Report of Seminars at the University of Michigan, July 1956. Studies of the Aged and Aging; Selected Documents. Washington, D. C., U. S. Government Printing Office, 1957, vol. 9, p. 61-72.

2. Dasco, M. M.: The teaching of geriatric concept in medical schools, Geriatrics 13: 102$105,1958$.

3. Harlan, W. H.: The training of the professional educator in social gerontology, Adult Education 9: 67-74, 1959.

4. Foundation and Government Support for Social Gerontology: A Survey Report, Newsletter, Gerontological Society 5: 7-8 (Sept.) 1958. 